\title{
Effect of Dipeptidyl peptidase-4 inhibitors on the progression of atherosclerosis in patients with type 2 diabetes mellitus: a meta-analysis of randomized controlled trials
}

\author{
Hongshuo Shi ${ }^{1}$, Yufan $\mathrm{Liu}^{1}$, Min Peng ${ }^{2}$, Zunqi Kan ${ }^{1}$, Wenwen $\mathrm{Li}^{1}$, and Tiantian Yang ${ }^{2}$ \\ ${ }^{1}$ Shandong University of Traditional Chinese Medicine \\ ${ }^{2}$ Shandong Provincial Hospital
}

December 19, 2020

\begin{abstract}
Objectives: Type 2 diabetes mellitus(T2DM) can accelerate the clinical process of atherosclerosis(AS). Dipeptidyl peptidase-4 inhibitors(DPP-4Is) have potential anti-AS effects. And, we completed a meta-analysis of the changes in carotid intima-media thickness(CIMT), flow-mediated dilation(FMD), and pulse wave velocity(PWV) of DPP-4Is to research the effect of DPP-4Is in the progression of AS in T2DM patients. Materials and methods: We included RCTs that evaluated the impact of DPP-4Is on CIMT, FMD, and PWV compared to other treatments from PubMed, Cochrane trials, and Embase database before October 31, 2020. We selected the random-effect model and calculated the weighted mean difference(WMD) to evaluate the effect of CIMT, FMD, and PWV in T2DM patients. Results:Through the meta-analysis, we found that DPP-4Is can significantly reduce CIMT in T2DM patients(WMD =-0.036, 95\% CI:-0.055 to-0.017; p[?]0.001). Based on the subgroup analysis, we found that CIMT was significantly decreased in patients with greater than 12 months of intervention and without cardiovascular diseases. Besides, we also found that DPP-4Is had a not significant efficacy on the improvement of FMD in T2DM patients(WMD=0.635, 95\% CI: -0.112 to $1.383, \mathrm{p}=0.097$ ). Our subgroup analysis showed that for T2DM patients who have cardiovascular diseases, DPP-4Is can significantly increase their FMD. In addition, we also found that DPP-4Is had an insignificant influence on PWV in T2DM patients $(\mathrm{WMD}=0.424,95 \%$ CI: -0.198 to $1.046, \mathrm{p}=0.18)$. but SGLT2 inhibitors may reduce the PWV of T2DM patients. Conclusions: DPP-4Is can alleviate the development of AS in T2DM patients to a certain extent by reducing CIMT. And, we believe that long-term use of DPP-4Is may be more helpful to alleviate the atherosclerotic development of T2DM without obvious cardiovascular history.
\end{abstract}

\section{Hosted file}

manuscript.pdf available at https://authorea.com/users/383830/articles/499658-effect-ofdipeptidyl-peptidase-4-inhibitors-on-the-progression-of-atherosclerosis-in-patientswith-type-2-diabetes-mellitus-a-meta-analysis-of-randomized-controlled-trials

\section{Hosted file}

Figure 1.pdf available at https://authorea.com/users/383830/articles/499658-effect-ofdipeptidyl-peptidase-4-inhibitors-on-the-progression-of-atherosclerosis-in-patientswith-type-2-diabetes-mellitus-a-meta-analysis-of-randomized-controlled-trials

\section{Hosted file}

Figure 2.pdf available at https://authorea.com/users/383830/articles/499658-effect-ofdipeptidyl-peptidase-4-inhibitors-on-the-progression-of-atherosclerosis-in-patientswith-type-2-diabetes-mellitus-a-meta-analysis-of-randomized-controlled-trials 


\section{Hosted file}

Figure 3.pdf available at https://authorea.com/users/383830/articles/499658-effect-ofdipeptidyl-peptidase-4-inhibitors-on-the-progression-of-atherosclerosis-in-patientswith-type-2-diabetes-mellitus-a-meta-analysis-of-randomized-controlled-trials

\section{Hosted file}

Figure 4.pdf available at https://authorea.com/users/383830/articles/499658-effect-ofdipeptidyl-peptidase-4-inhibitors-on-the-progression-of-atherosclerosis-in-patientswith-type-2-diabetes-mellitus-a-meta-analysis-of-randomized-controlled-trials

\section{Hosted file}

Figure 5.pdf available at https://authorea.com/users/383830/articles/499658-effect-ofdipeptidyl-peptidase-4-inhibitors-on-the-progression-of-atherosclerosis-in-patientswith-type-2-diabetes-mellitus-a-meta-analysis-of-randomized-controlled-trials

\section{Hosted file}

Table 1.pdf available at https://authorea.com/users/383830/articles/499658-effect-ofdipeptidyl-peptidase-4-inhibitors-on-the-progression-of-atherosclerosis-in-patientswith-type-2-diabetes-mellitus-a-meta-analysis-of-randomized-controlled-trials

\section{Hosted file}

Table 2.pdf available at https://authorea.com/users/383830/articles/499658-effect-ofdipeptidyl-peptidase-4-inhibitors-on-the-progression-of-atherosclerosis-in-patientswith-type-2-diabetes-mellitus-a-meta-analysis-of-randomized-controlled-trials

\section{Hosted file}

Table 3.pdf available at https://authorea.com/users/383830/articles/499658-effect-ofdipeptidyl-peptidase-4-inhibitors-on-the-progression-of-atherosclerosis-in-patientswith-type-2-diabetes-mellitus-a-meta-analysis-of-randomized-controlled-trials 